\title{
N $93-30859$
}

\section{COMPARISON OF HAND LAID-UP TAPE AND FILAMENT WOUND COMPOSITE CYLINDERS AND PANELS WITH AND WITHOUT IMPACT DAMAGE}

\author{
Dawn C. Jegley and Osvaldo F. Lopez \\ NASA Langley Research Center \\ Hampton, VA
}

\section{INTRODUCTION}

Composite materials can be used to construct lightweight, structurally efficient components for aircraft applications. Graphite-epoxy parts can be used to replace many aluminum parts on today's aircraft. However, the low density and high stiffness and strength of laminated composites does not necessarily make them practical alternatives to metals for all applications. Fabrication techniques used to construct composite parts differ from those used to construct metal parts. Until recently most graphite-epoxy parts were fabricated from unidirectional tape involving an expensive and labor intensive procedure. Other methods of construction, such as filament winding, could significantly reduce the cost of fabrication and may improve the quality of some structures. However, few studies of the effects on structural response of fabrication-induced defects, such as fiber cross-overs (caused during filament winding of off-axis layers), are available. These defects could cause the structural response of hand laidup tape and filament wound specimens of the same stacking sequence to differ significantly.

The structural response of hand laid-up tape and filament wound cylinders and flat panels subjected to axial compressive loading and impact damage is presented in the present paper. A series of tests were conducted on graphite-epoxy cylinders of the same nominal dimensions and stacking sequence constructed using filament winding and using unidirectional hand laid-up tape. These cylinders were loaded to failure in axial compression. Some filament wound cylinders had fiber cross-overs while others did not. Flat graphite-epoxy panels were filament wound with fiber cross-overs and without fiber cross-overs and loaded to failure in axial compression. Additionally, some specimens were subjected to low speed impact damage prior to compressive loading. A comparison between the structural response of control (unimpacted) and impact damaged cylinders and flat panels is also presented. 
Descriptions of the thirty-six graphite-epoxy specimens tested are presented in figure 1. Eight cylinders and eight flat panels were constructed by filament winding. Eleven cylinders and nine flat panels were constructed by hand laying unidirectional tape. Half the filament wound specimens were constructed with fiber cross-overs and half had no fiber cross-overs. (None of the tape specimens had fiber cross-overs). Cylinders had a nominal radius-to-thickness ratio of 9 and a length-to-radius ratio of 4.8. Two dimensions of flat panels were used, some with a length-to-width ratio of 2.5 and a length-to-thickness ratio of 70 and some with a length-to-width ratio of 2.0 and a length-to-thickness ratio of 40 . Two families of stacking sequences, $[ \pm 45 / 90]_{n s}$ and $[ \pm 30 / 90]_{n}$, were considered. Two material systems were considered. All cylinders and all hand-laid tape panels were constructed from Hercules Incorporated AS4 graphite fiber and 3502 epoxy resin. The filament wound panels were constructed from Celion $6 \mathrm{k}$ graphite fiber and Shell Epon 9400 epoxy resin.

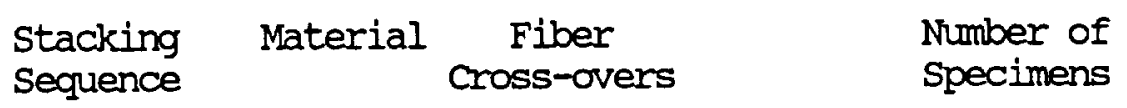

\section{Filament Wound Cylinders}

$\begin{array}{llll}{[ \pm 45 / 90]_{3 S}} & \text { AS4-3502 } & \text { Yes } & 4 \\ {[ \pm 45 / 90]_{3 S}} & \text { AS4-3502 } & \text { No } & 4\end{array}$

Hand Laid-up Tape Cylinders

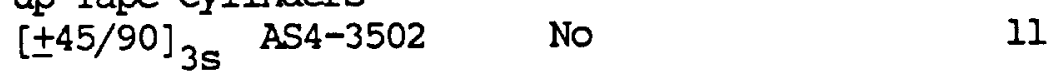

Hand Laid-up Tape Panels

$\begin{array}{llll}{[ \pm 45 / 90]_{4 S}} & A S 4-3502 & \text { No } & 8 \\ {[ \pm 30 / 90]_{16}} & A S 4-3502 & \text { No } & 1\end{array}$

Filament Wound Panels

\begin{tabular}{llll}
{$[ \pm 30 / 90]_{10}$} & $K 6-9400$ & Yes & 4 \\
{$[ \pm 30 / 90]_{10}$} & $K 6-9400$ & No & 4 \\
\hline
\end{tabular}


A filament wound cylindrical specimen with a band of fiber cross-overs around the circumference in the axial center of the specimen is shown in figure 2. Four specimens were filament wound and cut to length in this configuration. Four specimens were filament wound and cut to length in a configuration with no fiber cross-overs in the test section. Each cylinder is six inches long and has an inner diameter of 2.5 inches. The ends of each cylindrical specimen were potted in one inch of an epoxy material prior to testing, simulating clamped loaded edges. A hand laid-up tape specimen which has been potted and gaged with interior and exterior back-to-back strain gage rosettes is also shown in figure 2. This specimen has the same nominal dimensions as the filament wound specimen. All cylinders were constructed from AS4-3502 graphite-epoxy material. Loaded edges were ground flat and parallel prior to loading to ensure uniform edge displacement during loading. One side of each specimen was painted white so a moire fringe technique could be used to monitor out-of-plane displacements during the test.
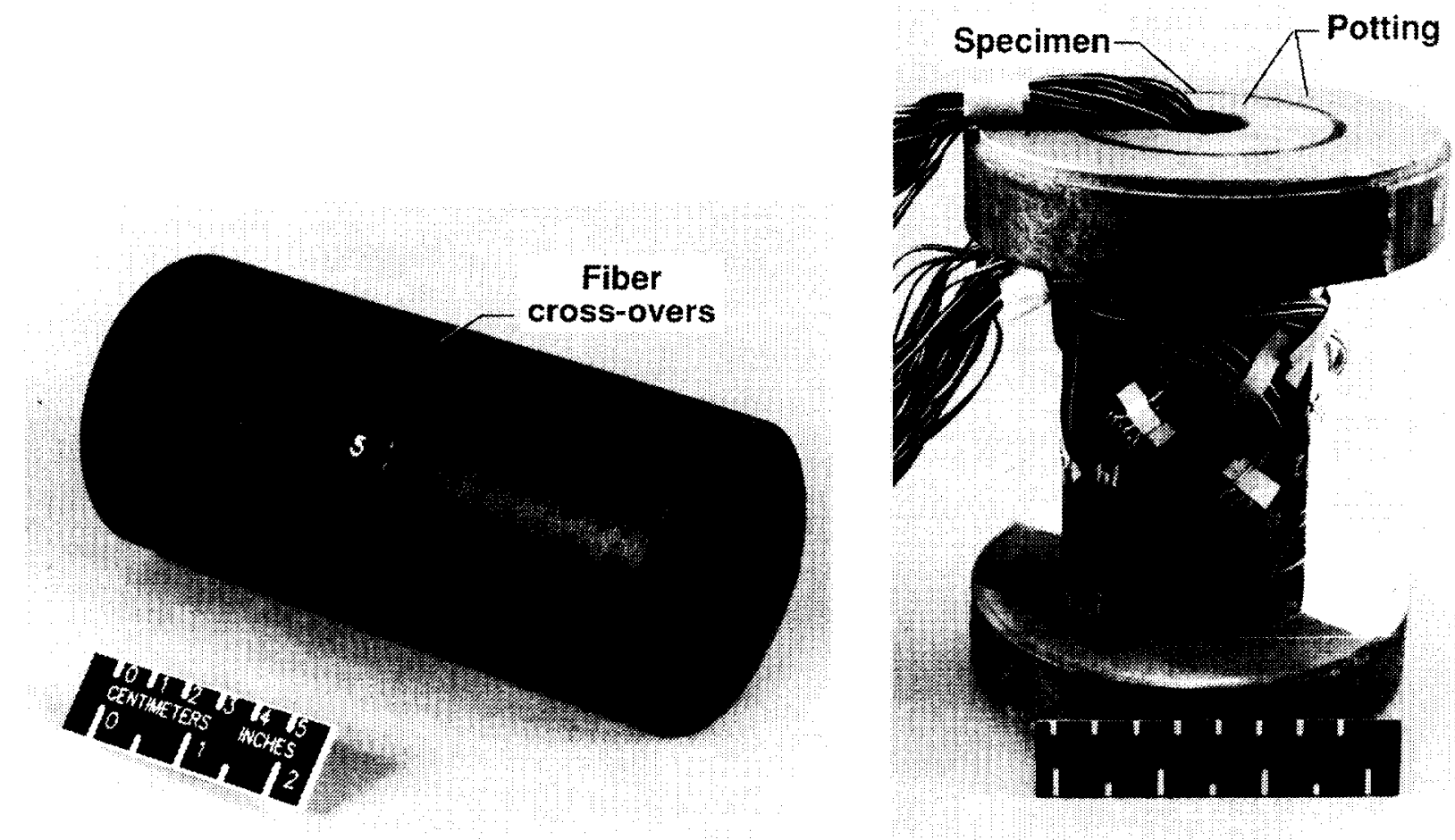

Figure 2 
Eight filament wound flat plate specimens with stacking sequence $[ \pm 30 / 90]_{10}$, one hand laid-up tape flat plate specimen with stacking sequence $[ \pm 30 / 90]_{16}$ and eight flat plate specimens with stacking sequence $[ \pm 45 / 90]_{4 \mathrm{~s}}$ were loaded to failure in axial compression. All flat plates had clamped loaded edges and simple support knife edge constraints on the unloaded edges during testing. A photograph of two specimens after loading in axial compression is shown in figure 3. A filament wound plate specimen is shown on the left side of the photograph and a hand laid-up tape plate specimen is shown on the right. Fiber cross-overs can be seen in the filament wound plate. Four filament wound plates had fiber cross-overs and four did not. Each plate with stacking sequence $[ \pm 30 / 90]_{n}$ is five inches wide, ten inches long and approximately .25 inches thick.

A delamination failure occurred near the top of the tape specimen along the loaded edge. The filament wound specimen delaminated and failed along a fiber cross-over band located at the center of the plate. Each flat control (unimpacted) specimen buckled immediately prior to failure. One control specimen of each type was tested and the rest were subjected to impact damage prior to compressive loading.

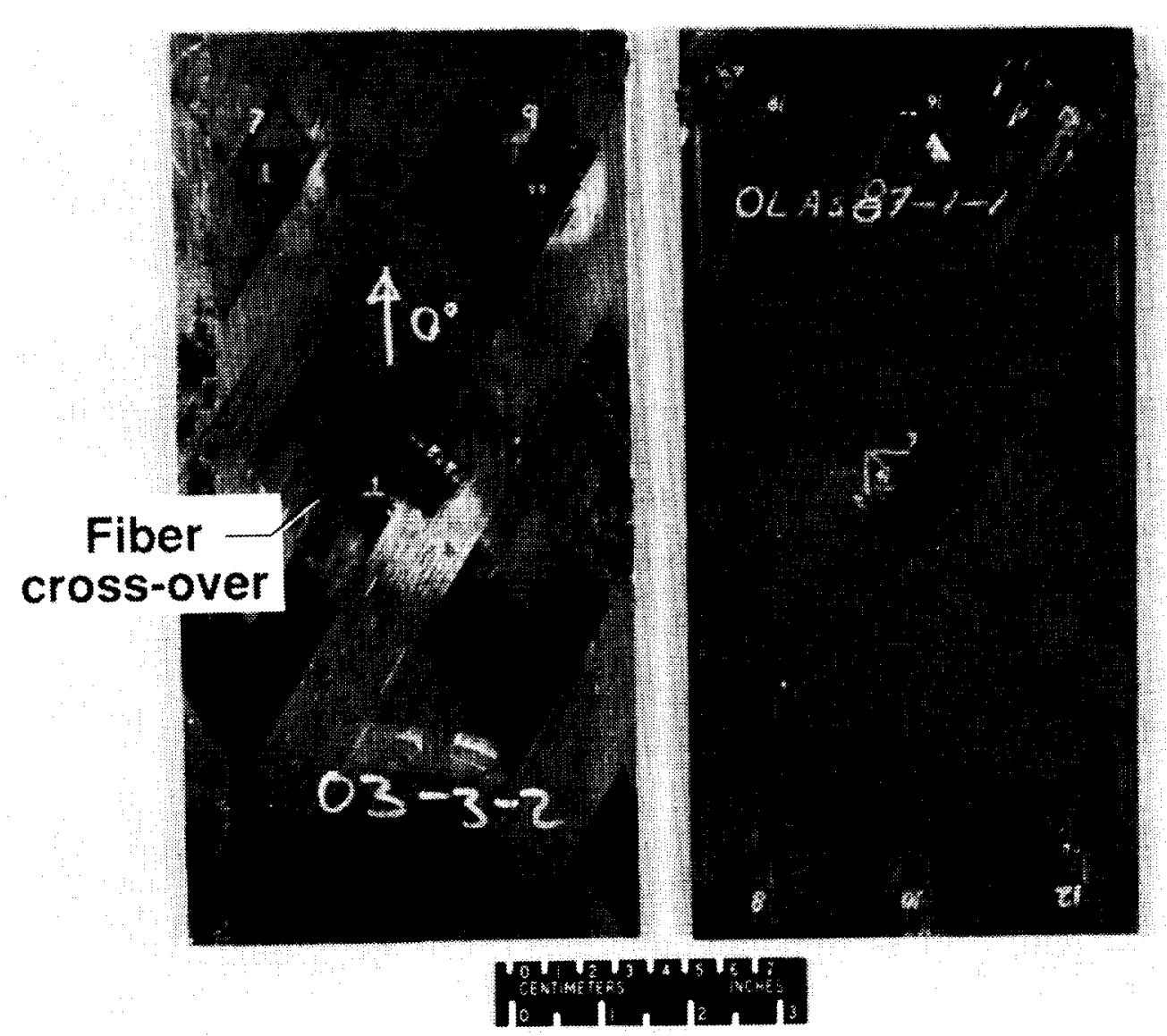

Figure 3 
Five control (unimpacted) filament wound and six control hand laid-up tape cylinders with stacking sequence $[ \pm 45 / 90]_{3 s}$ were loaded in axial compression to failure. Three filament wound specimens had fiber cross-overs midlength. Two cylinders had no fiber cross-overs in the test section. Failure strains based on measured end shortening $\delta$ and initial specimen length $L$ of each control cylinder are shown in figure 4 . The symbols in the figure represent the failure strain $\delta / L$ of each specimen and horizontal bars represent average failure strains of specimens of each type. Individual data points are shown to demonstrate the scatter in failure strains within each group. A small difference in average failure strains between the filament wound specimens with and without cross-overs can be seen from the data; however, scatter in the data indicates that this difference may be an artifact of the limited number of specimens tested. The scatter range for the tape specimens also suggests that there is no real evidence of a difference in failure strain among the three type of specimens.

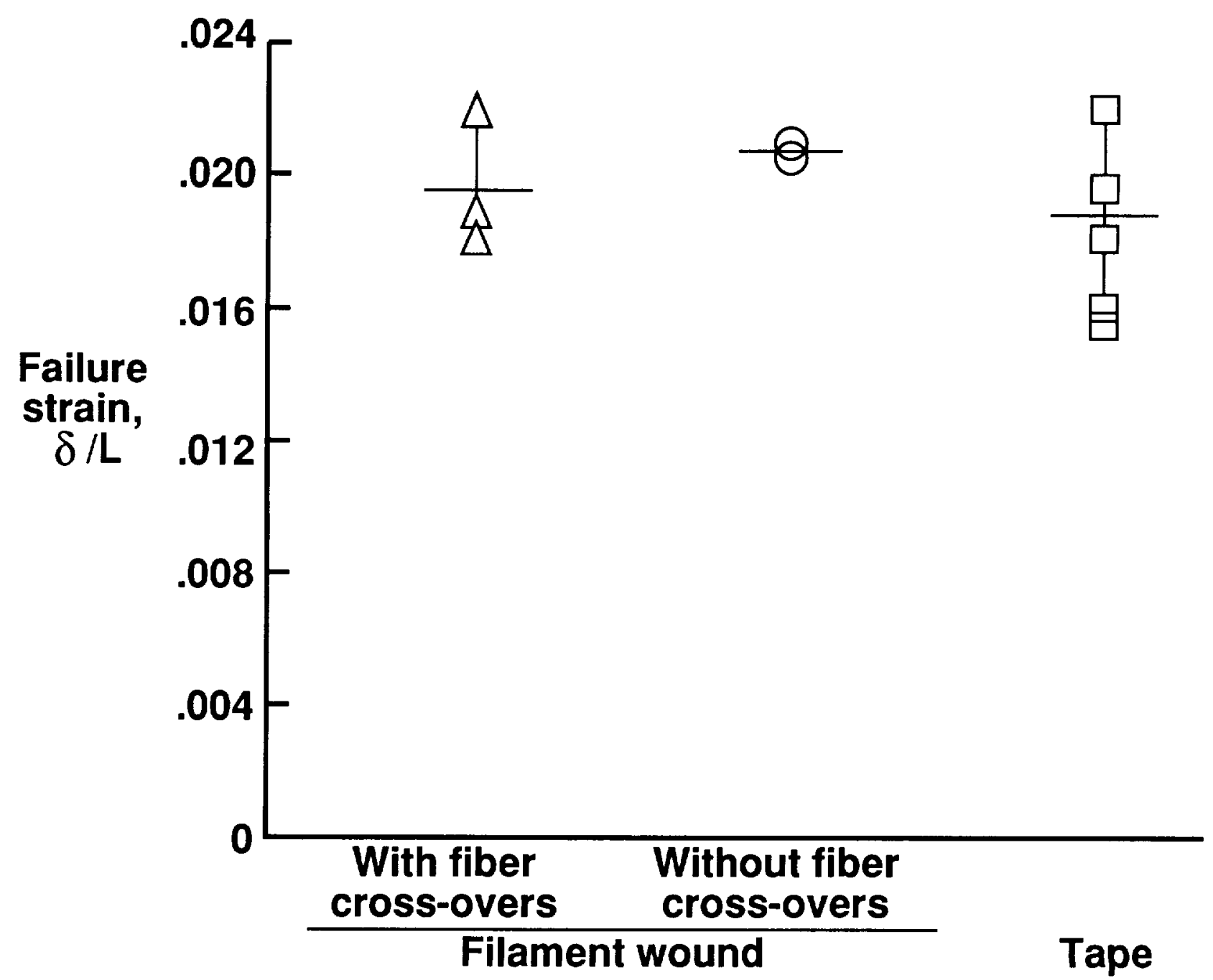

Figure 4 
The relationship between normalized load $P / E A$ (where $P$ is applied load, $E$ is specimen axial stiffness and $A$ is specimen cross-sectional area) and normalized displacement $\delta / L$ (where $\delta$ is end shortening and $L$ is initial specimen length) for two typical control cylinders is shown in figure 5 . The axial stiffness calculated from experimental data in the linear-elastic range indicate that the filament wound cylinder's average stiffness is about 5 percent below that of the tape specimens. When cross-sectional area is considered, this difference reverses. The average EA for the filament wound cylinders is 420,000 lb while the average EA for the tape cylinders is $380,000 \mathrm{lb}$. In both types of cylinders, the scatter of values for EA among the cylinders tested is about 8 percent while the scatter for $E$ is about 20 percent. However, the load-displacement relationship is nonlinear in both types of cylinders and the stiffness decreases when the average strain is above about .01 in both types of specimens.

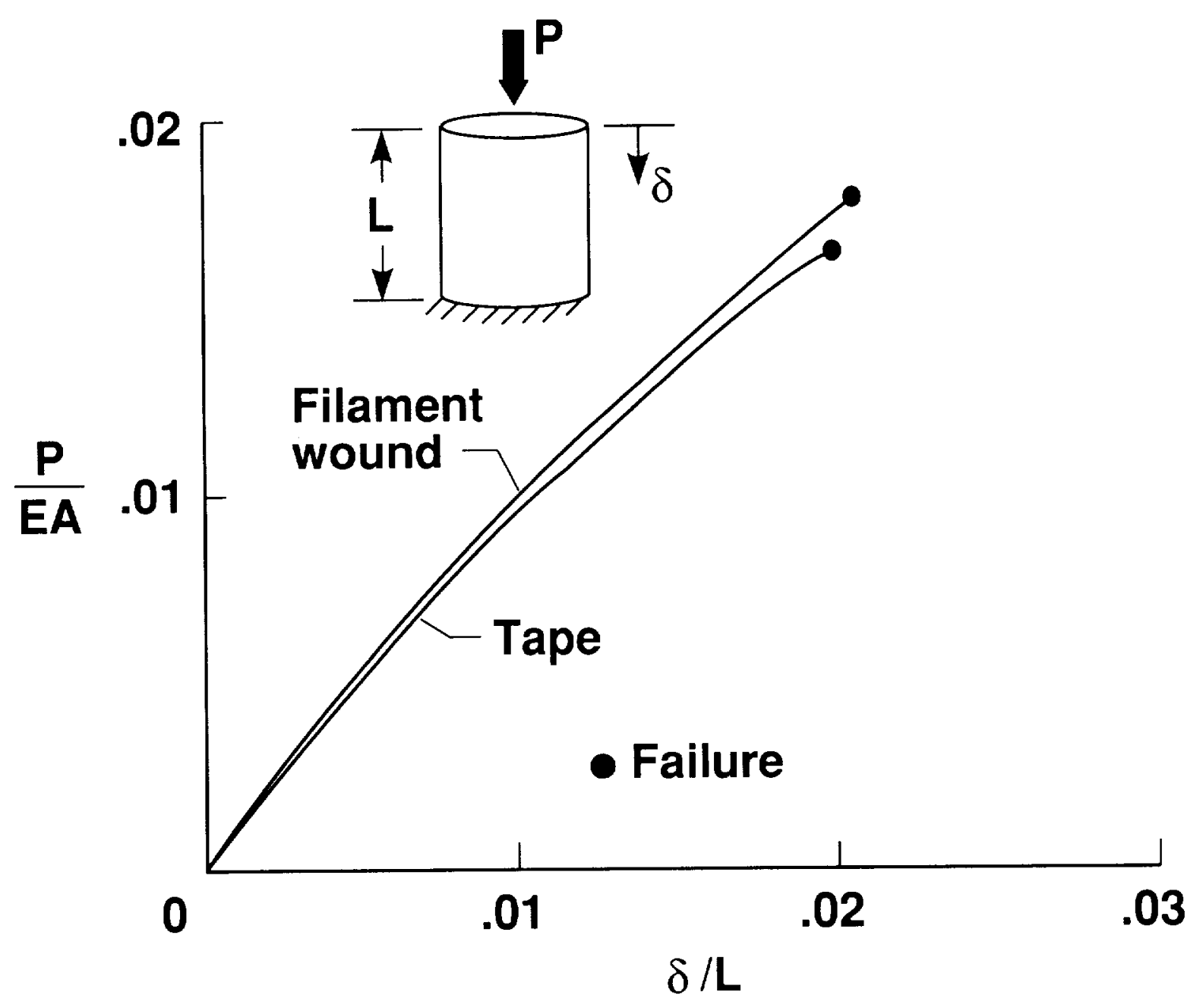

Figure 5 


\section{FAILED GRAPHITE-EPOXY TAPE CYLINDER}

Photographs of a graphite-epoxy tape cylinder after failure are shown in figure 6. The entire specimen is shown to demonstrate the extent of damage induced at failure. The damage region extends around the entire circumference and over one third or more of the length of the test section and is concentrated around the axial centerline. The failure mode involved delamination of the innermost and outermost plies. Delaminated fibers broke, leading to specimen failure. Little visible or audible warning occurred prior to failure. Failure quickly progressed around the circumference of the tube. Measured axial surface strains were just over .02 at failure for each specimen. Strain gages in the direction of the outermost fibers ( 45 degrees) recorded a failure strain in the range of .007 to .008. A close-up view of one section of the cylinder is also shown on the right of the figure to show that the exterior layers of fibers pulled away from the cylinder during failure. The outer two plies are of stacking sequence +45 and -45 degrees. Both of these plies separated from the interior plies of the cylinder. The same failure mode was seen in the filament wound cylinders as in the tape cylinders.

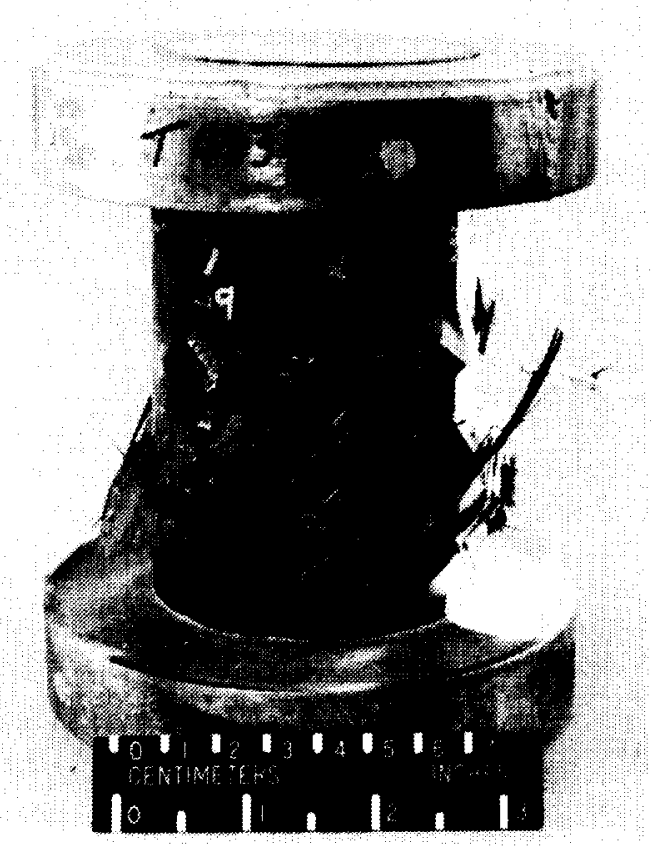

Figure 6

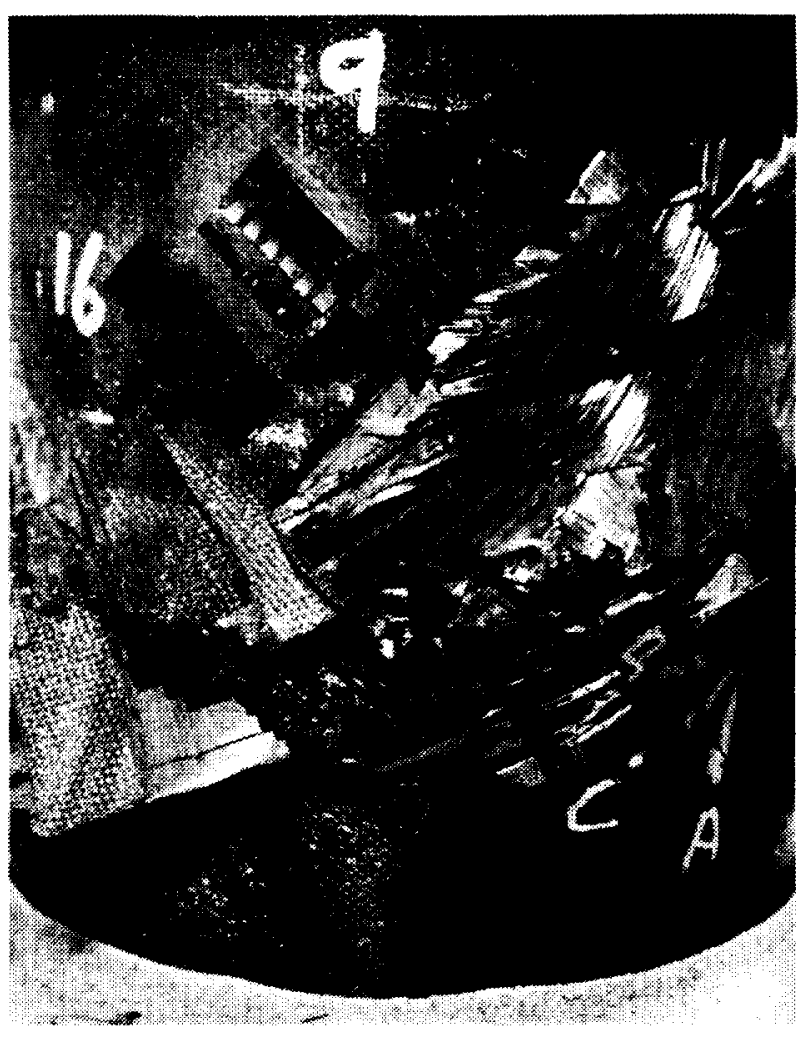


Impact damage was induced into many specimens by propelling a .5 -inchdiameter aluminum sphere at the center of the specimen at a specified speed (as described in reference 1). Three filament wound and four hand laid-up tape cylinders with stacking sequence $[ \pm 45 / 90]_{3 s}$ were impacted prior to loading with impact speeds up to $400 \mathrm{ft} / \mathrm{sec}$ (impact energies up to $16 \mathrm{ft}$ 1b). All cylinders were impacted at mid-length. Seven hand laid-up tape flat panels with stacking sequence $[ \pm 45 / 90]_{4 \mathrm{~s}}$ were impacted at the center

of the panel prior to loading. All specimens had a nominal thickness of .14 inches. The failure strain of each impacted specimen and the average failure strain of all control specimens of each type are shown in figure 7. These results indicate that impact damage reduces the failure strain to approximately 60 percent of the average failure strain of unimpacted specimens for impact speeds over $200 \mathrm{ft} / \mathrm{sec}$ (impact energy $4 \mathrm{ft}-1 \mathrm{~b}$ ) for filament wound and tape cylinders. Failure modes for impacted cylinders were the same as for unimpacted cylinders. All cylinders failed at the mid-length of the specimen (through the impact site). Flat panels impacted at speeds above $200 \mathrm{ft} / \mathrm{sec}$ did not buckle prior to failure and failed through the impact site. Flat panels failed at lower axial strains than the cylinders for each impact speed. However, this difference is most pronounced in the control specimens where the flat panel buckled and the cylinders did not. The percentage reduction in failure strain in flat panels is smaller because the flat control specimen failed at a lower strain than the cylindrical control specimens. The minimum failure strain of each type of specimen is achieved for impact speeds above $200 \mathrm{ft} / \mathrm{sec}$. This minimum threshhold is lower for the flat panels than for the cylinders because of curvature effects.

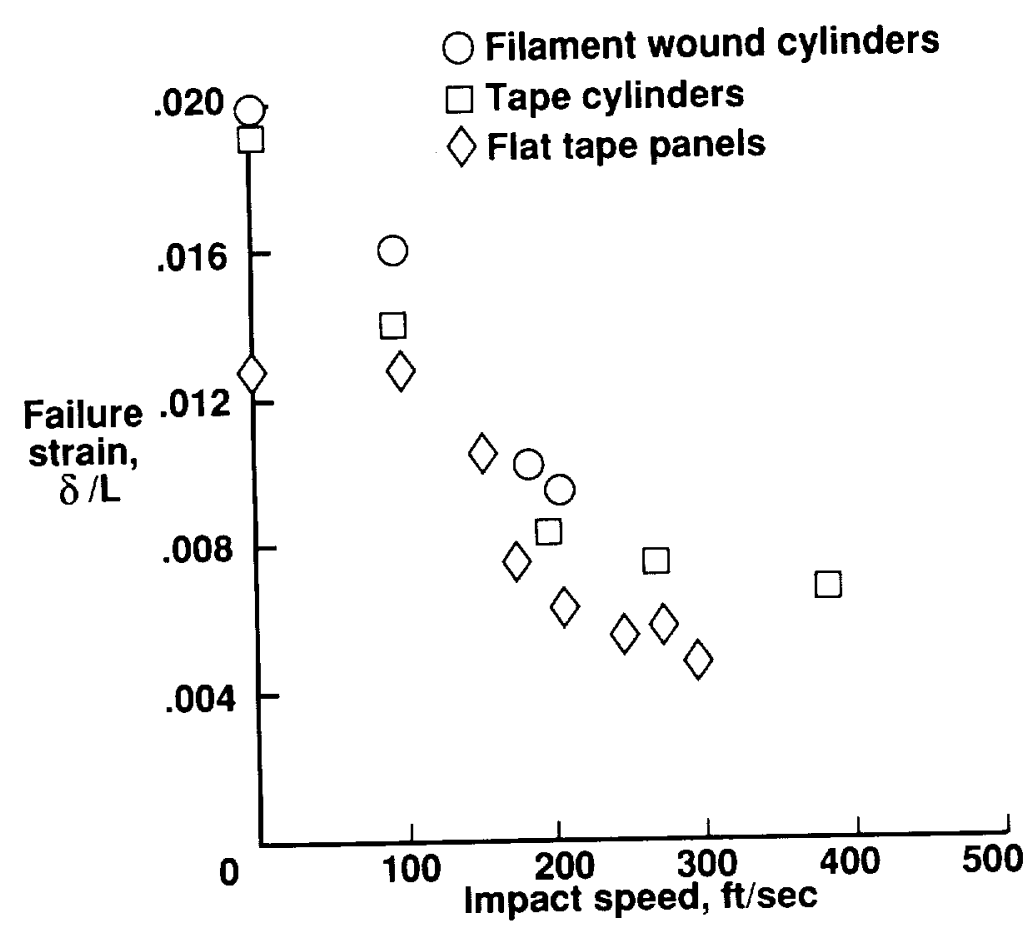

Figure 7 
The relationship between normalized load $\mathrm{P} / \mathrm{EA}$ and normalized end shortening $\delta / L$ for three control plate specimens with stacking sequence $[ \pm 30 / 90]_{n}$ is shown in figure 8. Two of the control specimens are filament wound plates. One filament wound plate contains fiber cross-overs and the second plate does not. The third control specimen is a hand-laid tape plate (with no fiber cross-overs). The filament-wound plates were fabricated from Celion $6 \mathrm{k}$ fiber and Shell Epon 9400 resin and the tape-laid plate was fabricated from AS4/3502 prepreg tape.

The test results indicate a similar load-displacement behavior between the filament-wound plate with fiber cross-overs and the tape-laid plate; however, since these plates were fabricated from different materials, the similarity may not be caused by factors relating to plate construction. A stiffness comparison of nominally identical plates constructed of the two material systems indicate that the AS4-3502 plate has a noticably higher bending stiffness than the Celion $6 \mathrm{k}-9400$ plate. However, the loaddisplacement response differs in the two filament-wound plates. For example, at an end shortening of .0095 in/in, a 20 percent difference is obtained in normalized load between both filament-wound plates. This comparison suggests that fiber cross-overs may affect the load-displacement response in filament-wound plates.

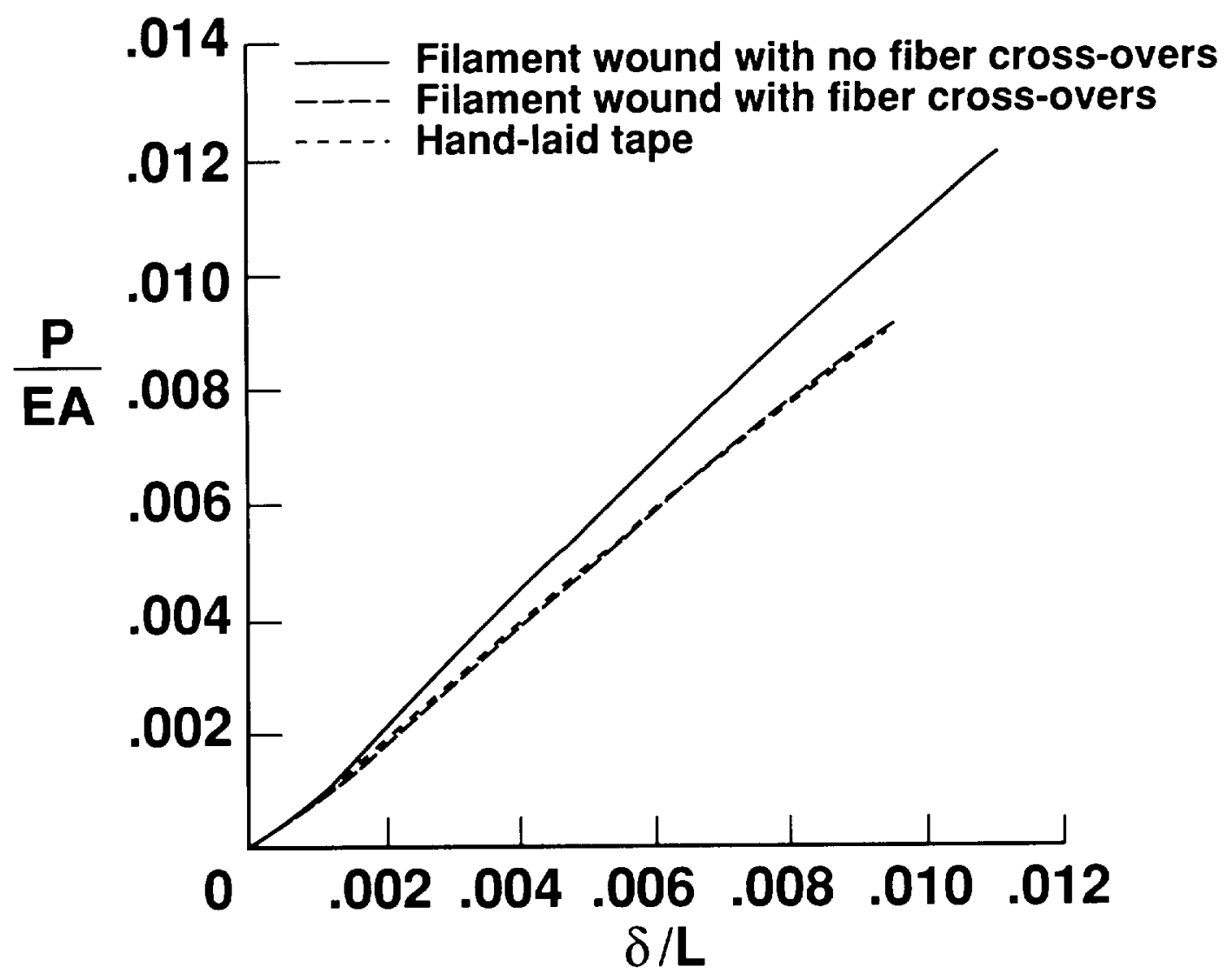

Figure 8 
The relationship between failure strain and impact speed for eight filamentwound plate specimens with stacking sequence $[ \pm 30 / 90]_{10}$ and one hand laid-up tape plate specimen with stacking sequence $[ \pm 30 / 90]_{16}$ is shown in figure 9 . Six plate specimens were impacted at the center of each specimen with a. 5 inch-diameter aluminum sphere at speeds ranging from 300 to $500 \mathrm{ft} / \mathrm{sec}$. Three of the impacted specimens contained fiber cross-overs and three did not. The failure strain for three control (unimpacted) specimens is also shown.

The results of these compression-after-impact tests indicate that for all impact speeds examined, the plate specimens without fiber cross-overs failed at higher strains than specimens with fiber cross-overs. This comparison suggests that fiber cross-overs can affect the performance of filament-wound plates. The percentage difference in failure strain for the two types of specimens diminishes as the impact speed increases. At an impact speed of $300 \mathrm{ft} / \mathrm{sec}$, a 30 percent reduction in failure strain is obtained for specimens with fiber cross-overs compared to specimens which have no fiber cross-overs. However, at an impact speed of $500 \mathrm{ft} / \mathrm{sec}$, the difference in failure strain between specimens with and without fiber cross-overs is only 12 percent.

The results also show that failure strain decreases as impact speed increases for specimens with fiber cross-overs and for specimens without fiber cross-overs. Specimens impacted with an impact of speed $500 \mathrm{ft} / \mathrm{sec}$ failed at a strain level less than half that of the control specimen for each type of specimen.

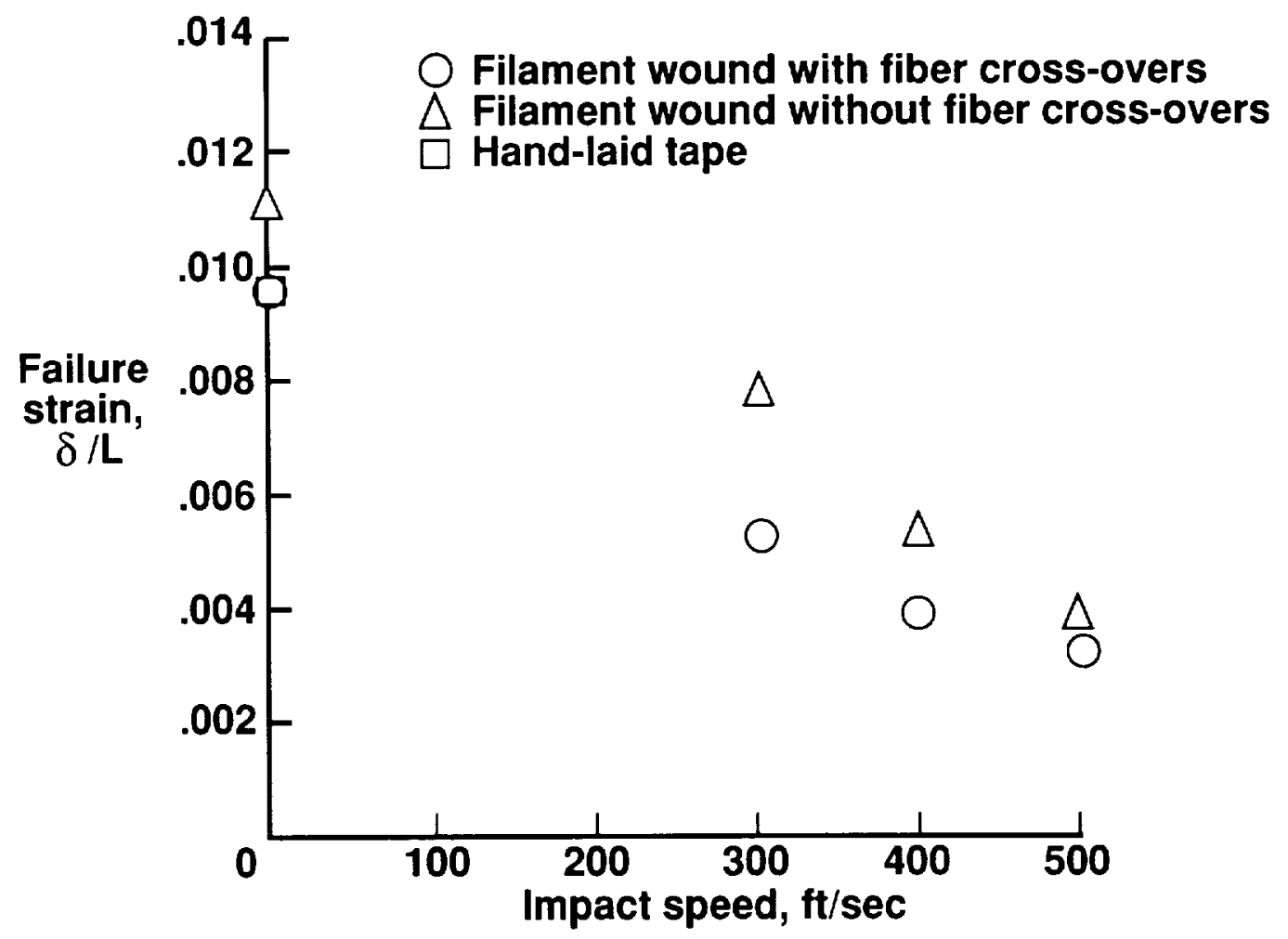

Figure 9 


\section{CONCLUDING REMARKS}

The results of this experimental comparison of filament wound control (unimpacted) cylinders loaded to failure in axial compression indicates that one fiber cross-over location has no effect on the failure mode or strain in thick-walled filament wound graphite-epoxy specimens with stacking sequence $[ \pm 45 / 90]_{3 \mathrm{~s}}$. A comparison between filament wound and hand laid-up tape control cylinders indicates that there is little or no difference in the response of cylinders constructed by using the two different fabrication methods. However, unimpacted panels with many fiber cross-overs fail at up to 15 percent lower strains than panels with no fiber cross-overs.

A comparison of specimens subjected to low speed impact damage prior to compressive loading indicates that impact damage reduces the strain at failure by over 60 percent in tape and filament wound graphite-epoxy cylinders and in tape flat panels. The presence of fiber cross-overs were observed to reduce the strength of filament wound impact-damaged panels, but to have no significant effect on the strength of filament wound impactdamaged cylinders.

\section{REFERENCES}

1. Starnes, J. H., Jr.; Rhodes, M. D.; and Williams, J. G.: Effect of Impact Damage and Holes on the Compression Strength of a Graphite/Epoxy Laminate. Nondestructive Evaluation and Flaw Criticality for Composite Materials, edited by R. B. Pipes, ASTM STP 696, 1979, pP. 145-171. 
